\title{
Pengenalan printing 3D dan software Autodesk Fusion untuk guru dan siswa SMK di eks karisidenan Surakarta
}

\author{
${ }^{1}$ Onery Andy Saputra, ${ }^{2}$ Sudiro \\ Teknik Mesin Otomotif, Politeknik Indonusa Surakarta, Surakarta, Indonesia \\ *Corresponding Author \\ onery@poltekindonusa.ac.id
}

\begin{abstract}
Abstrak
Salah satu teknologi yang saat ini mulai dimanfaatkan masyarakat untuk memproduksi komponen yaitu printing tiga dimensi. Printing tiga dimensi merupakan alat bantu membuat komponen otomotif dari desain tiga dimensi menjadi komponen nyata. Kebermanfaatan alat printing 3 dimensi ini ke depan sangat besar, pada saat membutuhkan komponen kita hanya perlu mendesain komponen tersebut didalam aplikasi dan selanjutnya dicetak menggunakan printing tiga dimensi. Permasalahan guru dan siswa SMK otomotif yang membutuhkan komponen otomotif yang langka dapat diantisipasi dengan penggunaan printing tiga dimensi. Alat printing tiga dimensi mampu membuat komponen sesuai dengan kebutuhan dari guru dan siswa. Sehingga guru dan siswa otomotif memerlukan pengetahuan dan pelatihan mengenai printing tiga dimensi beserta cara pembuatan komponen dengan alat printing tiga dimensi. Sehingga pelatihan printing tiga dimensi sangat bermanfaat bagi siswa dan guru. Tempat pelaksanaan pelatihan dilakukan di Laboratorium Politeknik Indonusa Surakarta. Waktu pelaksanaan pelatihan adalah tanggal 3 November 2018. Peserta pelatihan yaitu guru dan siswa SMK se-karisidenan Surakarta, dengan jumlah guru 12 dan siswa sebanyak 10 siswa dari SMK-SMK di wilayah Surakarta. Pelatihan dilakukan dengan metode penyampaian materi serta pelatihan dan diskusi. Hasil pelaksanaan pelatihan ini yaitu peserta pelatihan mendapatkan pengetahuan dan wawasan mengenai software untuk desain 3 Dimensi yang gratis untuk dunia pendidikan. Peserta juga mendapatkan keterampilan membuat desain 3 Dimensi dalam aplikasi Autodesk Fusion 360. Serta keterampilan yang diperoleh oleh peserta yaitu keterampilan pembuatan desain 3 dimensi sekaligus melakukan cetak desain yang dibuat menjadi benda yang nyata dalam bentuk 3 dimensi.
\end{abstract}

Kata kunci: 3D, printing, pelatihan, guru.

\begin{abstract}
One technology that is currently being used by the community to produce components is to print three dimensions. Printing three dimensions into a tool makes automotive components from three-dimensional design a real component. The usefulness of this 3-dimensional printing tool is very large, when a component is needed we only need to design the component in the application and then need to use three-dimensional printing. The problem of automotive vocational teachers and students who need automotive components that can be anticipated by using threedimensional printing. Three-dimensional printing tools are able to make
\end{abstract}


components according to the needs of the teacher and students. Related to automotive teachers and students, knowledge and training about three-dimensional printing is needed in how to make components with three-dimensional printing. Printing three-dimensional training is very beneficial for students and teachers. The place for conducting the training was conducted at the Indonusa Surakarta Polytechnic Laboratory. The time for the training is November 3, 2018. The trainees are vocational teachers and students from Surakarta residency, with 12 teachers and 10 students from Vocational Schools in the Surakarta region. The training was conducted with the method of delivering material and training and discussion. The results of the training are that trainees gain knowledge and insights about software for 3-dimensional design that is free for the world of education. Participants also obtained 3-dimensional design skills in the Autodesk Fusion 360 application. As well as the skills gained by participants, they were three-dimensional design skills to create designs that were made into real objects in 3-dimensional form.

Keyword: 3D, printing, training, teacher

\section{PENDAHULUAN}

\section{Latar Belakang}

Perkembangan teknologi yang ada di dunia industri sangat pesat. Perkembangan teknologi di dunia industri merupakan tuntutan dari iklim bisnis, iklim bisnis menuntut adanya kecepatan kepresisisan dan efisiensi. Dunia industri untuk merealisasikan kebutuhan tersebut maka membutuhkan teknologi. Berdasarkan tuntutan tersebut maka saat ini perkembangan teknologi sangat pesat. Perkembangan teknologi yang pesat tersebut saat ini sudah diberi nama dengan dengan revolusi industri 4.0. Revolusi industri 4.0 menurut Angela Merkel (2014) berpendapat bahwa industri 4.0 adalah transformasi komprehensif dari keseluruhan aspek produksi di industri melalui penggabungan teknologi digital dan internet dengan industri konvensional (Prasetyo, 2018). Teknologi yang berkembang dalam dunia industri otomotif yaitu salah satunya printing 3 dimensi. Teknologi ini merupakan terobosan baru untuk menciptakan komponen otomotif yang mampu dibuat dalam sekala kecil atau jumlah sedikit. Selain itu, printing 3 dimensi memiliki keakuratan sampai dengan $0.1 \mathrm{~mm}$ sehingga sangat cocok untuk dunia otomotif. Proses pengerjaan dari proses desain sampai dengan produk jadi juga tidak membutuhkan waktu lama, sekitar 1-2 hari saja. Sehingga pembuatan produk dapat dibuat sewaktu-waktu sesuai kebutuhan (Dewayana et al., 2012).

Tuntutan dunia industri yang sesuai dengan uraian di atas masih jauh dari penerapan kurikulum di SMK. SMK masih cendereng menerapkan model pembelajaran lama yaitu model kurikulum yang kurang mampu mengikuti perkembangan teknologi. Hal ini tercermin di dalam perubahan kurikulum SMK yang terjadi pada tahun 2004, 2006, dan yang terakhir pada tahun 
2013 (Slameto, 2017). Jangka waktu perubahan kurikulum yang panjang sangat sulit Pendidikan Atas khususnya SMK mengikuti perkembangan teknologi, hal ini didasarkan pada perubahan teknologi sangat cepat bisa jadi setiap bulan bahkan setiap harinya ada perubahan teknologi yang ada di dunia ini. Kondisi tersebut mengekang pendidikan SMK untuk tidak melakukan inovasi dan penyesuaian perkembangan jaman, dampak yang ditimbulkan dari kondisi tersebut yaitu kemampuan lulusan dari SMK kurang sesuai dengan kebutuhan dunia industry (Fakhri and Yufridawati, 2003).

Kondisi yang saat ini terjadi di dunia industri otomotif yaitu, perkembangan jumlah kendaraan yang semakin tinggi di pasar Indonesia menjadi peluang yang besar terhadap kebutuhan komponen otomotif. Kebutuhan komponen otomotif yang semakin banyak sangat menyulitkan distributor komponen kesulitan dalam pemenuhan permintaan pasar. Hal ini disebabkan karena jenis komponen otomotif yang semakin banyak karena setiap jenis kendaraan memiliki spesifikasi dan bentuk yang berbeda beda, maka jika distributor ingin menyediakan komponen tersebut dibutuhkan jenis komponen yang banyak dari berbagai merk (Kemenperin, 2018). Kondisi ini menjadi kebutuhan dunia industri otomotif untuk menyediakan komponen otomotif yang dibutuhkan oleh konsumen.

Perkembangan teknologi baru yang saat ini sedang berkembang sangat memungkinkan untuk digunakan sebagai alat untuk mencetak atau membuat komponen kendaraan bermotor yaitu Printer 3 Dimensi (Wattimena, 2019). Alat ini adalah solusi yang menjadi kendala dari distributor komponen otomotif. Solusi ini harusnya menjadi peluang besar pihak pendidikan atas untuk ikut serta menjadi produsen komponen otomotif yang sesuai dengan kebutuhan dunia pasar otomotif. Namun, kendala yang ada pihak pendidikan atas atau SMK belum ada yang bergerak atau merealisasikan peluang ini agar ke depan lulusan dari SMK mampu bersaing dengan di dunia industri. Beberapa masalah yang membuat pihak SMK belum merealisasikan hal tersebut karena pemahaman mengenai teknologi baru printing 3 dimensi belum dimiliki pihak SMK.

\section{Urgensi dan Rasionalisasi}

Prioritas permasalahan mitra guru dan siswa Mesin Otomotif se-Surakarta yaitu pengetahuan mengenai teknologi alat atau mesin yang dapat membuat komponen 3 dimensi dengan tingkat presisi yang tinggi. Pengetahuan mengenai prosedur penggunakan alat pencetak 3 dimensi. Proses skala prioritas yang perlu diselesaikan selama program PKM yaitu penjabaran pengetahuan teknologi mesin cetak 3 dimensi, workshop penggunaan alat printing 3 dimensi (Ahmadi, 2016). 


\section{Tujuan Kegiatan}

Tujuan dari pelaksanaan kegiatan pengabdian yaitu, 1) Memberikan pelatihan membuat desain 3 dimensi untuk guru dan siswa SMK se-Surakarta. 2) Memberikan pengenalan dan pelatihan printing 3 dimensi untuk guru dan siswa SMK se-Surakarta.

\section{Rencana Pemecahan Masalah}

Beberapa permasalahan yang dihadapi oleh mitra sudah dijelaskan pada uraian di atas. Maka pada bab ini akan dijabarkan solusi yang dapat dilaksanakan untuk menyelesaian permasalahan dari mitra. Beberapa solusi yang ditawarkan untuk menyelesaikan beberapa permasalahan tersebut adalah 1) Pelatihan aesain 3 Dimensi dengan aplikasi Autodesk Fusion (Tay, et al., 2017) ; 2) workshop desain 3 Dimensi dengan aplikasi Autodesk Fusion; 3) Pelatihan teknologi printing 3 dimensi (Arthaya, et al., 2015); 4) Workshop mencetak desain 3 dimensi.

\section{Analisis Situasi}

Kota Surakarta merupakan salah satu kota vokasi yang sudah ditetapkan pada tahun 2007 (R. Indonesia, 2019). Sehingga pendidikan yang ada di Surakarta mayoritas sudah mengarah pada pendidikan vokasi, yaitu pendidikan kejuruan. Banyaknya pendidikan kejuruan ini akan merupakan peluang yang besar untuk menyebarkan informasi teknologi terkini yang saat ini sedang berkembang. Salah satunya teknologi printing 3D yang sangat penting untuk diketahui masyarakat, khususnya mahasiswa Mesin Otomotif yang sering menggunakan maupun berinteraksi dengan alat tersebut (Anto, 2018).

Banyaknya lulusan dari kota vokasi juga merupakan peluang yang sangat besar untuk menyebarkan informasi teknologi. Dari lulusan ini pasti akan menyebar ke berbagai tempat sehingga informasi perkembangan teknologi ini akan sangat efektif untuk disebarluaskan kepada masyarakat Indonesia agar masyarakat Indonesia tidak ketinggalan informasi teknologi (R. Indonesia, 2018).

Kondisi pemahaman guru dan siswa SMK mengenai desain otomotif saat ini masih dalam pemahaman desain komponen dalam bentuk 2 dimensi dengan menggunakan kertas dan pensil, dan di beberapa SMK sudah ada yang menggunakan aplikasi CAD (Buncio, 2018) namun masih dalam bentuk 2 dimensi. Untuk desain 3 dimensi guru dan siswa masih belum mengaplikasikan dalam proses pembelajaran. Sehingga guru dan siswa untuk merealisasikan peluang yang terbuka sesuai kebutuhan dunia industri otomotif masih sangat jauh (Ahmadi, 2016). 


\section{METODE}

Metode yang digunakan untuk pelaksanaan pelatihan desain 3 dimensi yaitu, metode penyampaian materi, pelatihan keterampilan dan diskusi. Adapun tahapan penjabaran materi, yaitu tahap pertama pengenalan software desain, tahap kedua untuk konversi desain menjadi kode, serta tahap ketiga tahap printing tiga dimensi.

Pelaksanaan pelatihan dilakukan pada hari sabtu tanggal 3 November 2018. Pelaksanaan dilakukan di Laboratorium Desain Otomotif Politeknik Indonusa Surakarta. Pelaksanaan pelatihan selama 8 jam, mulai dari jam 8 sampai dengan jam 16.00. Peserta pelatihan merupakan guru dan siswa dari berbagai SMK di area Surakarta. Jumlah peserta pelatihan sebanyak 20 peserta dari 12 SMK yang berbeda.

\section{HASIL DAN PEMBAHASAN}

\section{Hasil}

Pelaksanaan kegiatan PKM berupa pelatihan ini dilakukan di bulan November 2018 dalam satu tahap rangkaian di Laboratorium Desain Otomotif Politeknik Indonusa Surakarta. Pelaksanaan Pelatihan dilakukan dalam 3 tahap, tahap pengenalan software desain, tahap kedua untuk konversi desain menjadi kode, serta tahap ketiga tahap printing tiga dimensi. Ketiga tahap pelatihan desain 3 dimensi ini dilakukan dalam satu hari hanya saja dilakukan pembagian waktu Runtutan pelaksanaan pelatihan yaitu sebagai berikut.

Peserta datang langsung diarahkan di laboratorium desain Politeknik Indonusa Surakarta. Sesampainya di depan laboratorium desain peserta diarahkan untuk menandatangai daftar hadir yang sudah disediakan. Sekaligus peserta mengecek kebenaran penulisan nama yang tertera dalam daftar hadir untuk pembuatan sertifikat. Setelah pengecekan nama selesai dan dinyatakan benar maka peserta diberikan konsumsi snack dan dipersilahakan masuk ke dalam laboratorium. Di dalam laboratorium peserta akan dipersilahkan masuk dan memilih komputer yang sudah disediakan. Sembari menunggu rekan-rekan yang belum datang peserta bisa melihat perangkat printing 3 dimensi serta produk yang sudah dihasilkan dari printing 3D.

Tahap pertama, tahap pertama yaitu mengenai software yang digunakan untuk membuat desain sekaligus untuk mengkonversi desain ke kode. Software yang digunakan yaitu Autodesk Fusion 360. Aplikasi ini merupakan aplikasi dari autodesk yang bagi pendidikan digratiskan. Langkah download instalasi serta pendaftaran akun gratis bagi pendidikan dapat dilihat dalam modul dalam pelatihan ini. Pengenalan software ini juga sampai dengan langkah pengenalan peralatan yang dapat digunakan dalam software tersebut. 


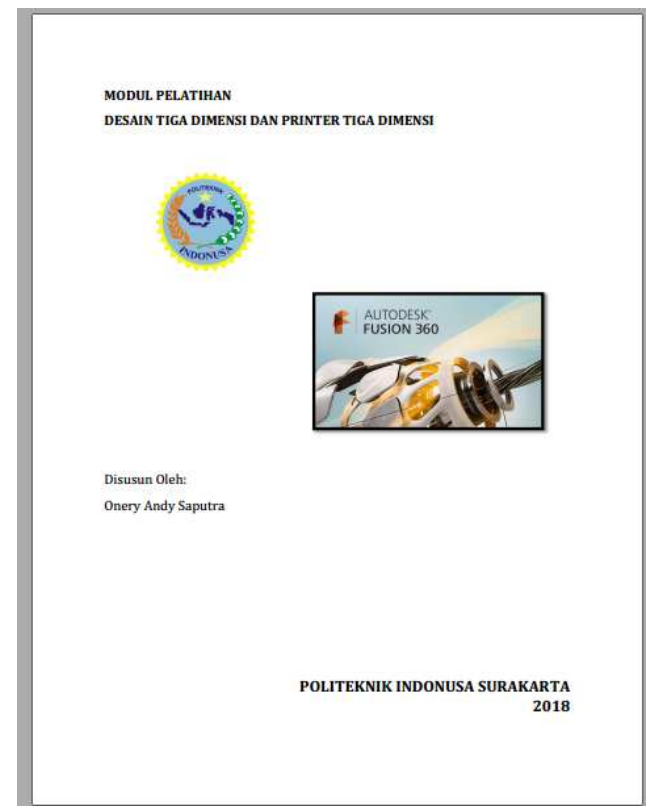

Gambar 1. Modul pelatihan Printing 3D.

Tahap kedua yang dilakukan dalam pelaksanaan pelatihan ini yaitu pembuatan desain 3 dimensi dengan software Autodesk Fusion sekaligus melakukan konversi dalam bentuk g.code atau bentuk file yang dibutuhkan dalam printing 3D atau peralatan yang lain yang membuat bentuk 3D. Aplikasi yang digunakan yaitu Repitier Host. Aplikasi ini juga dapat digunakan secara bebas atau sering disebut opensource.

Berikut desain yang dibuat dari hasil pelatihan 3D printing 3D di Politeknik Indonusa Surakarta yang dibuat di dalam aplikasi Autodesk Fusion 360.

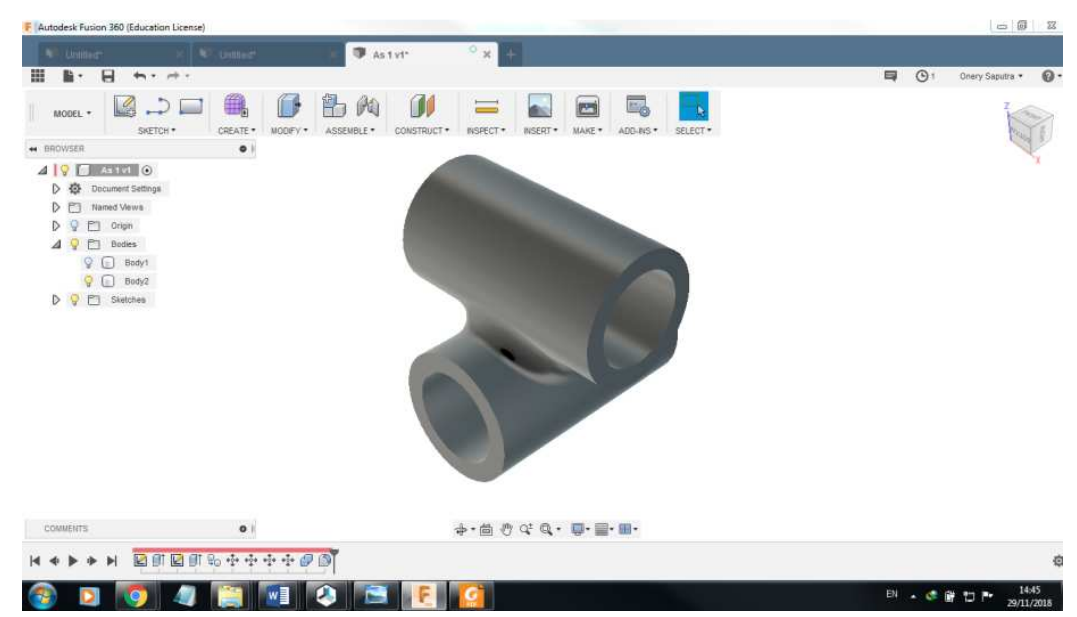

Gambar 2. Desain hasil pelatihan. 
Indonesian Journal of Community Services

E-ISSN: 2684-8619

Volume 1, No. 1, May 2019

http://jurnal.unissula.ac.id/index.php/ijocs DOI: http://dx.doi.org/10.30659/ijocs.1.1.83-94

Berikut suasana pada saat pembuatan desain 3 dimensi di dalam aplikasi Autodesk Fusion 360.

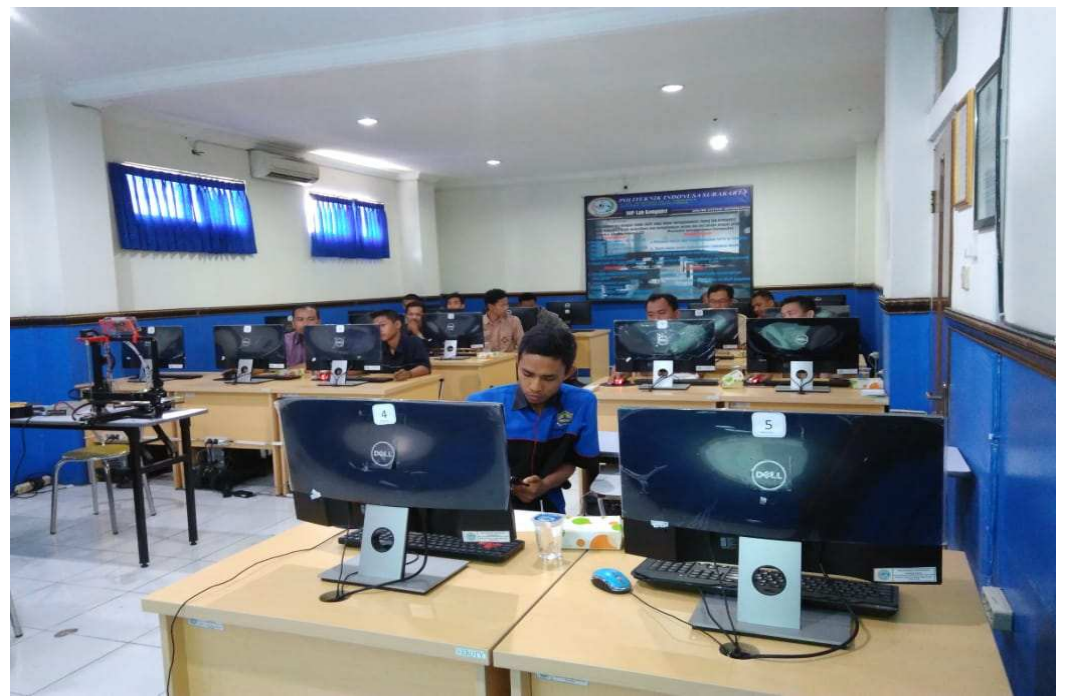

Gambar 3. Suasana pelaksanaan pembuatan desain 3D.

Setelah dikonversi di dalam repetier host maka desain 3D tersebut dapat menjadi sebagai berikut.

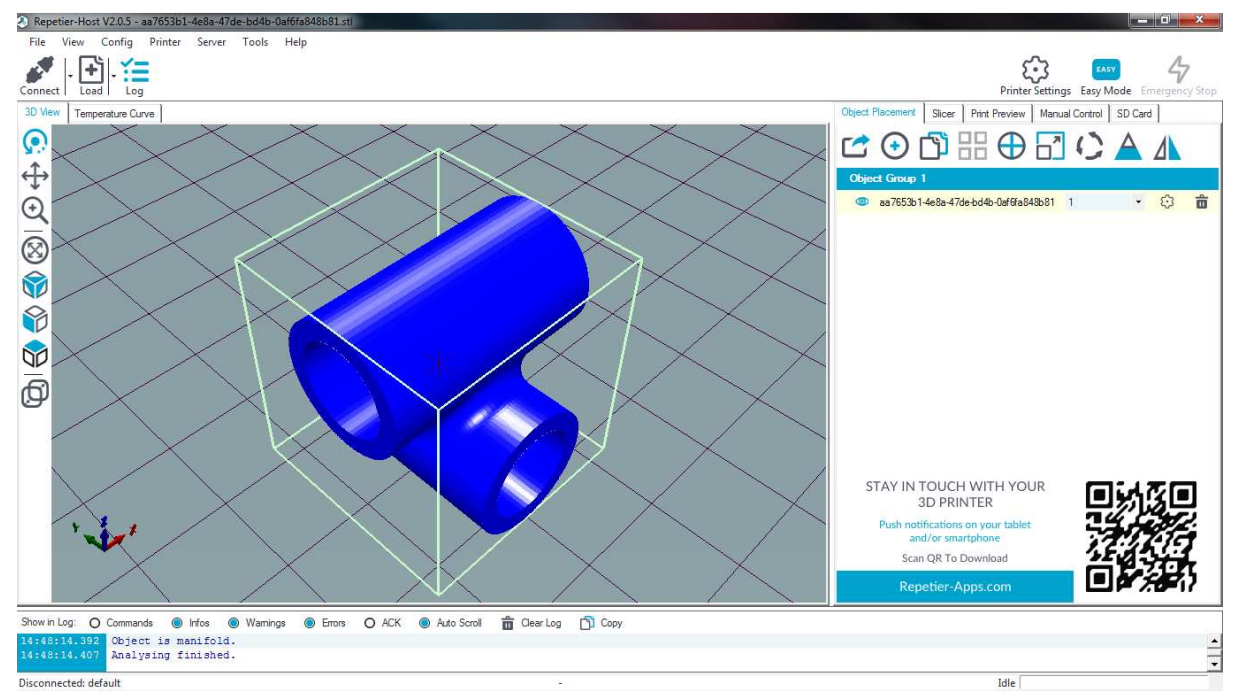

Gambar 4. Konversi 3D ke dalam Gcode

Tahap ketiga yaitu peserta diminta untuk menyimpan desain yang sudah dikonversi di dalam Gcode ke dalam MMC. Setelah file sudah dimasukkan ke dalam MMC peserta akan diberi arahan untuk mencetak desain di dalam printer 3 dimensi. Berikut proses pelaksanaan arahan mencetak gambar 3 dimensi. 


\section{Indonesian Journal of Community Services}

E-ISSN: 2684-8619

Volume 1, No. 1, May 2019

http://jurnal.unissula.ac.id/index.php/ijocs DOI: http://dx.doi.org/10.30659/ijocs.1.1.83-94

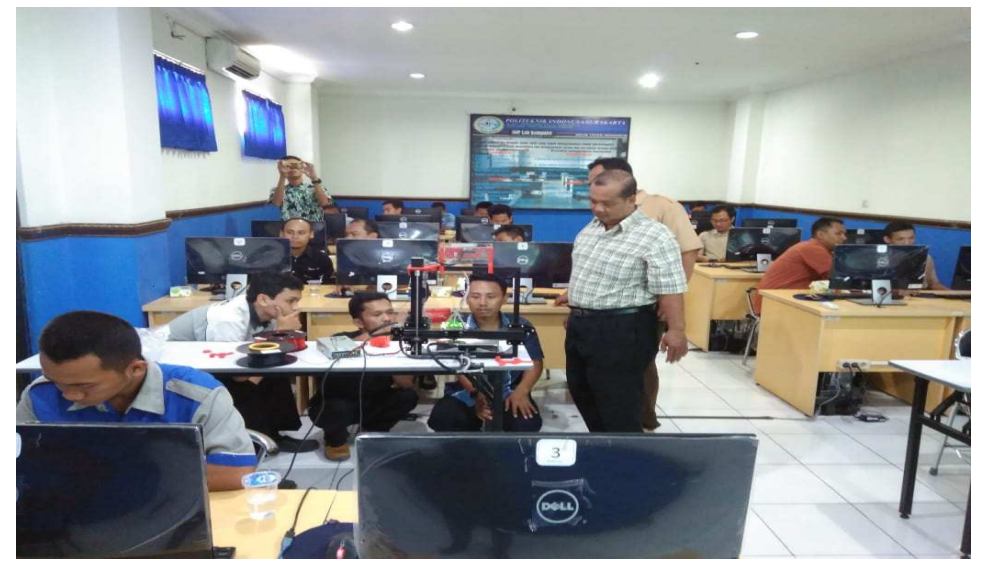

Gambar 5. Peserta melakukan demontrasi mencetak desain 3D di dalam printer 3D.

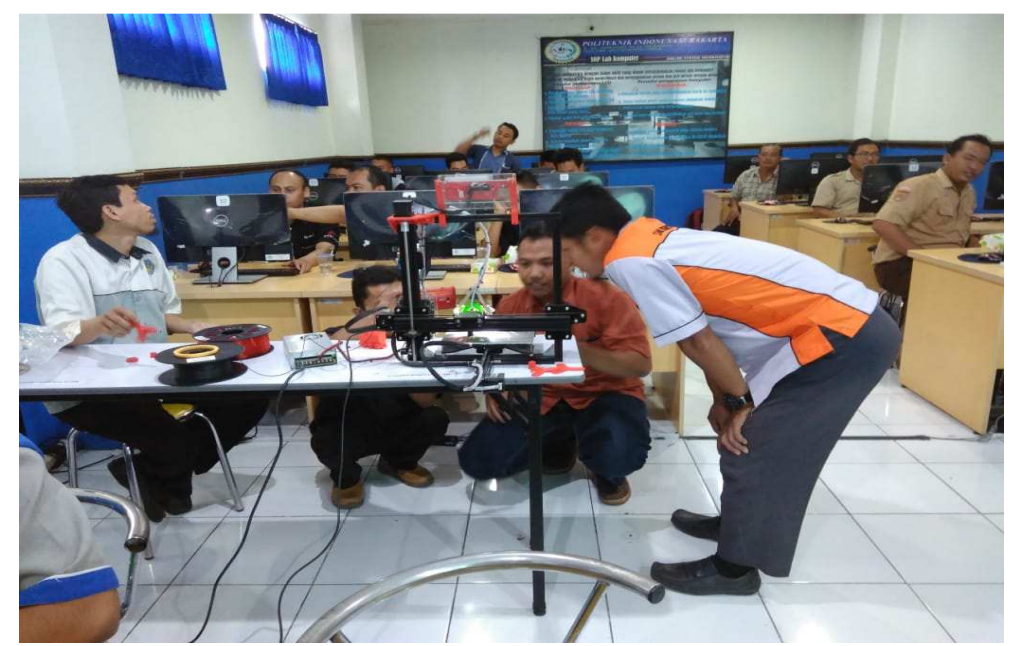

Gambar 6. Instruktur memberikan arahan pelaksanaan printing 3D.

\section{Hasil Praktek Peserta}

Hasil dari pelaksanaan pelatihan ini yaitu desain produk dan produk komponen otomotif. Pembagian hasil dilakukan dalam 2 bagian, yaitu untuk kriteria guru dan kriteria siswa. Berikut hasil yang sudah dibuat dari peserta pelatihan. 


\section{Indonesian Journal of Community Services}

E-ISSN: 2684-8619

Volume 1, No. 1, May 2019

http://jurnal.unissula.ac.id/index.php/ijocs DOI: http://dx.doi.org/10.30659/ijocs.1.1.83-94

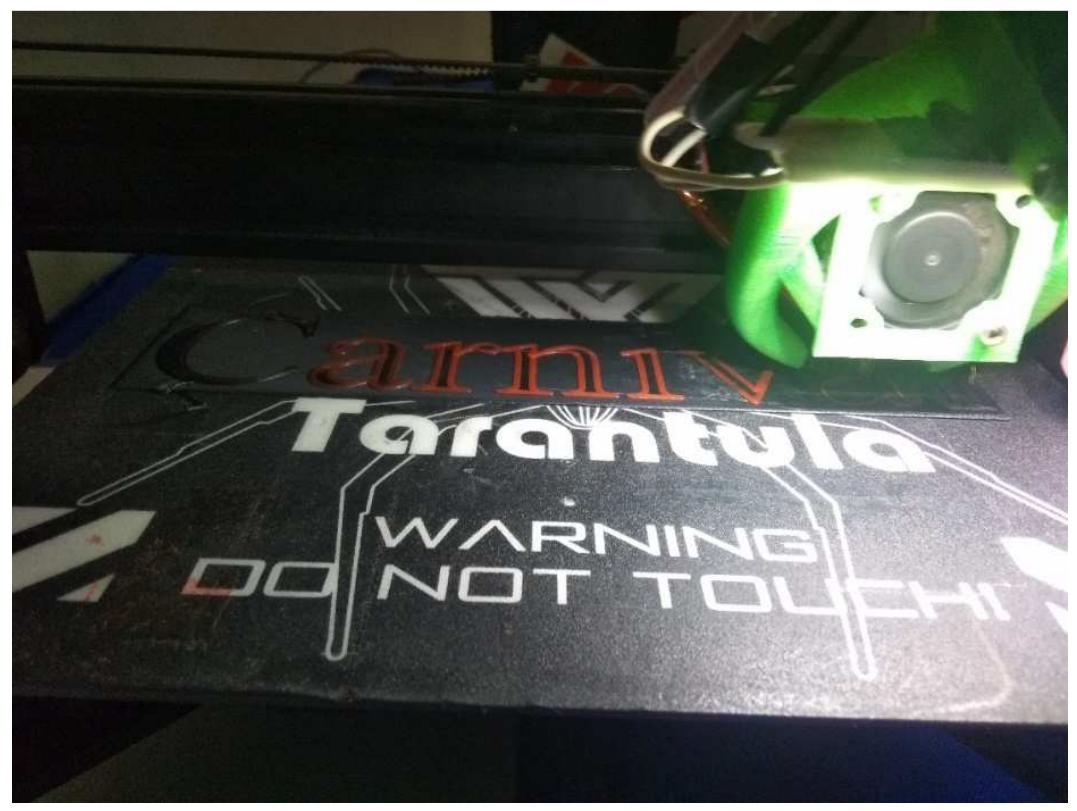

Gambar 7. Proses printing 3 dimensi.

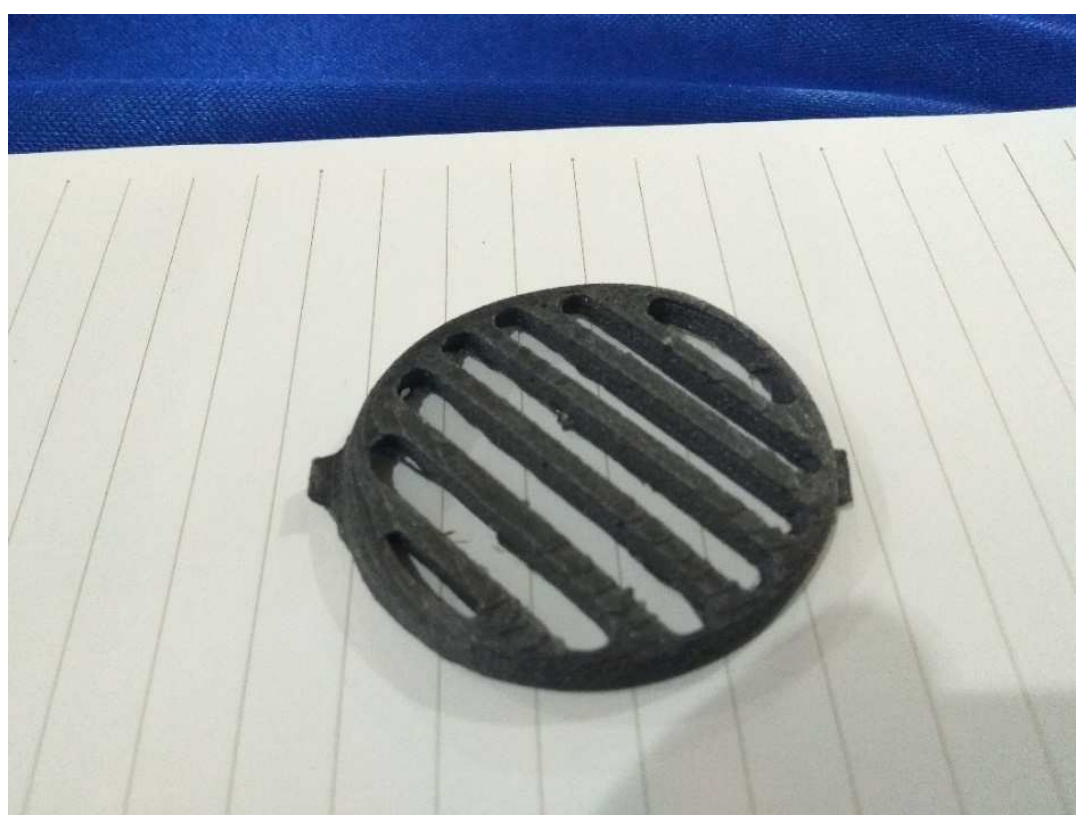

Gambar 8. Produk printing dari desain peserta.

\section{Pembahasan}

Analisis Kualitatif dari pelaksanaan kegiatan kegiatan ini yaitu sebagai berikut.

Secara umum hasil yang dibuat dari peserta pelatihan sudah relatif baik, hanya saja masih perlu perapian dan finishing agar hasil lebih maksimal. Hasil pengerjaan dari guru sangat baik karena guru relatif memiliki pengalaman dalam pembuatan desain 3 dimensi selama 
perkulihan dan untuk hasil printing dari guru juga relatif baik. Salah satu hasil printing dari peserta pelatihan ada di gambar 8. Produk printing dari desain peserta. Hasil pengerjaan siswa masih relatif banyak kendala, khususnya dalam proses pembuatan desain. Hal ini disebabkan siswa belum memiliki pengalaman dalam proses pembelajaran desain. Hasil printing juga masih jauh dari cukup, hal ini dikarenakan siswa masih cenderung menghabiskan waktu dalam proses pembuatan desain maka waktu printing tidak selesai.

Tindak lanjut dari hasil pembahasan pelaksanaan pelatihan ini yaitu perlu dilakukan pendampingan secara khusus untuk guru agar dapat menerapkan pembelajaran printing 3 dimensi di dalam proses pembelajaran di kelas. Perlu adanya kerja sama dan komunikasi dengan pihak jajaran pengambil keputusan agar sekolah memberi peluang dan kesempatam guru menerapkan pembelajaran printing 3 dimensi. Jika memungkinkan perlu diadakan perubahan kurikulum agar materi tersebut masuk dalam kurikulum pembelajaran, sehingga implementasi pembelajaran akan terjamin pelaksanaannya. Tindak lanjut bagi siswa sepenuhnya akan diarahkan kepada guru yang bersangkutan.

\section{KESIMPULAN}

Hasil kegiatan pelatihan ini ada beberapa hal antara lain:

1. Peserta mendapatkan pengetahuan dan wawasan mengenai software untuk desain 3 Dimensi yang gratis untuk dunia pendidikan. Peserta juga mendapatkan keterampilan membuat desain 3 Dimensi dalam aplikasi Autodesk Fusion 360. Serta keterampilan yang diperoleh oleh peserta, yaitu keterampilan pembuatan desain 3 dimensi sekaligus melakukan cetak desain yang dibuat menjadi benda yang nyata dalam bentuk 3 dimensi.

2. Desain 3 dimensi merupakan teknologi terbaru yang saat ini sedang berkembang, sehingga kedepan akan sangat membantu dalam pembuatan benda. Setiap orang akan mudah jika menginginkan sesuatu maka akan langsung membuat dengan cara menggambar dalam bentuk 3 dimensi dan langsung dicetak.

3. Perlu dilakukan pendampingan secara khusus untuk guru agar dapat menerapkan pembelajaran printing 3 dimensi di dalam proses pembelajaran di kelas. Perlu adanya kerja sama dan komunikasi dengan pihak jajaran pengambil keputusan agar sekolah memberi peluang dan kesempatam guru menerapkan pembelajaran printing 3 dimensi.

Printing 3 dimensi merupakan teknologi terbaru dalam dunia desain sehingga sangat perlu dilakukan sosialisasi di sekolah-sekolah agar sekolah tidak ketinggalan dalam hal 
teknologi. Sekolah yang tanggap dengan teknologi maka ke depan siswanya akan mudah beradaptasi dengan teknologi. Tantangan ke depan akan lebih mudah jika siswa sudah tanggap teknologi.

\section{UCAPAN TERIMA KASIH}

Pada kesempatan ini kami mengucapkan terima kasih yang sebesar-besarnya kepada:

1. Ir. Suci Purwandari, M.M. selaku Direktur Politeknik Indonusa yang telah memberikan kesempatan seluas-luasnya kepada kami untuk mengembangkan diri.

2. Kepala Unit Penelitian, Lembaga Penelitian dan Pengabdian kepada Masyarakat beserta stafnya yang telah memberikan banyak dukungan teknis, fasilitas, dan administrasi guna kelancaran pengabdian.

3. Guru dan Siswa SMK se-Surakarta yang telah bersedia bekerja sama dalam pelaksanaan pengabdian demi pengembangan kelompok belajar.

4. Teman-teman dosen, khususnya dari Program Studi D3 Mesin Otomotif yang telah memberikan dorongan dan semangat untuk menyelesaikan pengabdian ini.

5. Semua pihak yang tidak dapat kami sebutkan satu persatu yang telah banyak memberikan bantuan, arahan serta dorongan kepada kami dalam menyelesaikan pengabdian ini.

\section{DAFTAR PUSTAKA}

Anto. (2018). Norisanto.com. Norisanto.com, pp. 1-9, 09-Nov-2018.

Ahmadi, A. (2016). Menghaluskan hasil 3D Print. pp. 1-9, 2016.Prasetyo, W. S. H. (2018). Industri 4.0: Telaah Klasifikasi Aspek Dan Arah Perkembangan Riset," J. Tek. Ind., vol. 13, no. 1, p. 372.

Arthaya, B., \& Fransiscus, E.H. (2015). E. Kemampuan, D. A. N. Kapasitas, P. Dalam, P. Modul, R. Dan, and B. A. B. I. Pendahuluan. Lembaga Penelitian dan Pengabdian kepada Masyarakat Universitas Katolik Parahyangan,” pp. 1-34, 2015.

Buncio, A. D. “3D Printing in the Construction Industry | VIATechnik,” 2018.

Dewayana, T. S., Sugiarto, D., and Hetharia, D. (2012). Peluang dan Tantangan Industri Komponen Otomotif Indonesia, Pros. Semin., vol. 1, no. 2.

Fakhri, E. and Yufridawati. (2003). Relevansi Kompetensi dan Tingkat Daya Saing Lulusan SMK dalam Dunia Kerja ( Studi kasus pada SMK Teknik Otomotif di empat kabupaten / kota ), pp. 1-18, 2003.

Kemenperin, Industri Otomotif Ketergantungan Komponen Impor. pp. 3-5, 2018. 
Indonesian Journal of Community Services

E-ISSN: 2684-8619

Volume 1, No. 1, May 2019

http://jurnal.unissula.ac.id/index.php/ijocs DOI: http://dx.doi.org/10.30659/ijocs.1.1.83-94

R. Indonesia, (2019). Solo. pp. 1-5.

Slameto, S., Rasional dan Elemen Perubahan Kurikulum 2013. (2017). Sch. J. Pendidik. dan Kebud., vol. 5, no. 1, p. 1.

Tay, Y. W. D. et al. (2017). 3D printing trends in building and construction industry: a review. Virtual Phys. Prototyp., Vol. 12, no. 3, pp. 261-276.

Wattimena, R. M. (2019). Analisa Pembuatan Serbuk Tembaga Hasil Proses Electrorefining Metode Laboratorium, J. Politek. Negeri Semarang, pp. 1-5, 2019. 